\title{
PUBLIC RESPONSES TO THE CHERNOBYL ACCIDENT
}

\author{
ORTWIN RENN \\ Center for Technology, Environment, and Development (CENTED), \\ Clark University, 950 Main Street, Worcester, MA 01610, USA
}

\begin{abstract}
The reactor accident at Chernobyl caught many European nations by surprise since most risk management institutions were unprepared for an accident of the magnitude and transnational character of Chernobyl. Although confusion and contradictory advice from these institutions dominated the risk management efforts in the early aftermath of the disaster, the dose savings achieved by protective actions were roughly proportional to the magnitude of the nuclear threat. The accident itself and the policies adopted to cope with the fallout had a major effect on public opinion. This effect was the more dramatic and enduring, the more a country was affected by the fallout and the higher the percentage of indifferent positions toward nuclear power was prior to the accident. The media certainly intensified public concern, but did not distort the seriousness of the risk or create confusion about what protection actions were adequate. The major lesson from the disaster is to have a better risk management and communication program in place before a disaster strikes.
\end{abstract}

\section{Public Responses to the Chernobyl Accident}

The reactor accident at Chernobyl in the Soviet Ukraine on April 25-26, 1986, posed a threat of radioactive contamination to various countries. The event provided a unique experience for studying attitude changes and public reactions to an identical stimulus in a multi-cultural context. Since the risk management institutions of most affected countries were unprepared for an accident of the magnitude and transnational character of Chernobyl, it was necessary to improvise appropriate responses to the fallout. A particular problem was the highly nonuniform distribution of ground deposition produced by rainout (Hohenemser et al., 1986).

Both the disaster and the attempts to cope with the fallout situation had significant effects on public opinion and attitudes in the countries involved. Public responses were not only directed toward the origin of the disaster, the Chernobyl Nuclear Power Plant, but included general considerations about the acceptability of nuclear power, the domestic nuclear power program, and the efficacy of risk management in each country. Although the official positions of each country's government toward nuclear energy were rarely reversed after the accident (Flavin, 1987), public opinion shifted towards a more skeptical overall position towards nuclear power, in almost all affected countries. Opposition parties in West Germany and the United Kingdom responded with a decision to phase out nuclear energy if they were given the opportunity to take over the government.

The focus of this article is on four interrelated subjects: first, the official responses of risk management agencies and national governments are briefly described to provide a 
platform for the discussion of the public responses; second, the shift of public opinion in many affected countries is presented and discussed: third, attitude change and behavioral responses are examined and attempts are made to explain them by referring to attitude theory, institutional credibility, and mass media influence; and fourth, lessons for risk communication and management are formulated to reflect the results of our investigations of public reactions. Our analysis includes only the West European countries and (partially) the United States.

\section{Official responses of European governments to Chernobyl}

European risk management institutions faced a serious crisis when the fallout of the Chernobyl accident continued to travel from the East to the West. Most countries had no emergency plans for coping with accidents that occurred outside of their territory or outside the European community. Common standards were missing, and the ALARA (As Low As Reasonably Achievable) principle was often too vague to make fast, effective, and consistent decisions. In addition, the following factors aggravated the situation (Renn, 1986):

- lack of capability for food monitoring;

- lack of risk communication programs about the nature of the health effects from low dose radiation;

- problems of justifying different protective actions for different regions; and

- control of public responses (compliance with public recommendations, but avoidance of overreactions).

Most observers agree that the European countries had difficulties in overcoming these management problems. They apparently failed in granting optimal protection for the population at risk as well as in assuring the public that a clear and consistent management approach was taken (Otway et al., 1987; Wallmann, 1987). The confusion was heightened by the inconsistent use of units of measurement, the politicization of the issue by specific interest groups (for example, environmentalists and the nuclear industry), the public fear of radiation, and overlapping responsibilities (Otway et al., 1987; Roser, 1988).

As a case in point, on the West German side of Lake Constance dairy cattle were kept off pastures, and iodine milk levels peaked at around $100 \mathrm{Bequerel}$ per liter (Bq/1); whereas on the Swiss side, cattle grazed on the fresh fallout, and iodine milk levels peaked at around $1000 \mathrm{~Bq} / 1$ (Hohenemser \& Renn, 1988). Using a range of national reports, the general structure of protective actions for both eastern and western countries has been surveyed by the U.S. Interlaboratory Task Force (DOE, 1987). A similar, even more detailed data base has been prepared for OECD countries (NEA, 1988). The following list contains the most common measures and/or recommendations.

- informational activities, such as education about potential health effects and precautionary actions;

- recommendation to restrict outdoor activities such as keeping children indoors during rainfall; close swimming pools, playgrounds, and other public recreational facilities; and cancelling sport or other outdoor activities and events;

- measures to limit the ingestive pathway via controls on (1) rainwater for drinking by people and domestic animals; (2) open grazing by dairy cattle; (3) marketing of 
milk and dairy products; (4) banning of imported foodstuff; (5) washing of leafy vegetables; and (6) controlling meat sources (domestic cattle and game);

- efforts to limit external exposure via evacuation, sheltering, and administration of iodide pills (only Soviet Union);

- environmental controls, including requirements for changing industrial and hospital air filters and controls on the use of sewage sludge for soil amendment;

- compensation for agricultural losses.

How effective were these protective actions that have been or are still in effect in various countries? According to the U.S. Interlaboratory Task Force (DOE, 1987), the question cannot be usefully answered because the pattern of application is insufficiently clear, and the effect of future actions cannot be ascertained. At the same time, given the eight-day nuclear halflife of iodine 131 and the one-year halflife of cesium 137 in most food chains, one would expect most dose savings to occur in the first year. The Nuclear Energy Agency of the OECD (NEA, 1988) has asked member countries to estimate first year dose savings, with results shown in Table 1.

It is clear from the Table that collective dose savings varied widely. Hohenemser and Renn conducted a regression analysis to relate dose savings to concentration of radionuclides (Hohenemser \& Renn, 1988). In spite of the small data base, the correlation factor between dose savings and whole body dose is quite substantial. The authors calculated a correlation coefficient of $0 \cdot 70$.

The relationship between dose and dose saving indicates that most West-European nations acted in proportion to the nuclear threat. The collected data reflect, however, only national averages for both dose and dose reductions. Additional studies are needed to relate regional dispersion of radionuclides with dose savings. Anectodal evidence collected in Germany (Renn, 1986; Roser, 1988) and in France, Italy, and the

TABLE $1^{a}$

Estimates of first-year whole body dose savings from protective actions (in percent)

\begin{tabular}{|c|c|c|c|c|}
\hline \multirow[t]{2}{*}{ Country } & \multicolumn{4}{|c|}{ Collective dose saving } \\
\hline & Total & Infants & Children & Adults \\
\hline Austria & 50 & 53 & 50 & 50 \\
\hline Belgium & & $-\mathrm{v}$ & all - & \\
\hline Finland & $7 \cdot 2$ & 12 & 11 & $6 \cdot 3$ \\
\hline France & & $-v$ & all —_ & \\
\hline West Germany & 30 & (Ove & mate) & \\
\hline Greece & 23 & 25 & 17 & 24 \\
\hline Italy & 18 & 53 & 33 & 15 \\
\hline Luxembourg & $7 \cdot 5$ & 17 & 13 & $6 \cdot 6$ \\
\hline The Netherlands & 15 & 43 & 23 & 12 \\
\hline Norway & 32 & 29 & 28 & 33 \\
\hline Sweden & 15 & 0 & 3 & 17 \\
\hline Switzerland & 1 & 50 & 0 & 0 \\
\hline Turkey & 12 & 0 & 18 & 11 \\
\hline United Kingdom & 1 & $<1$ & 1 & 1 \\
\hline
\end{tabular}

${ }^{a}$ Source: Nuclear Energy Agency, The Radiological Impact of the Chernobyl Accident in OECD Countries (Paris: NEA 1988). 
United Kingdom (Otway et al., 1987) suggest that the allocation of dose reduction measures to local hot spots was insufficient and often counterproductive.

\section{Policy adjustments after Chernobyl}

In addition to management responses, most countries adopted policy changes in their domestic nuclear program. Soon after the accident, the Dutch parliament approved a motion to suspend a decision on the location of two nuclear reactors until a thorough analysis and evaluation of the Chernobyl accident had been completed (Nucleonic Week, 1986). In Yugoslavia, the Croatian parliament voted to reappraise the Prevlaka nuclear power plant. Sweden reaffirmed its national policy of terminating nuclear energy in the future and Austria confirmed its decision not to use nuclear energy.

West Germany reacted with the setting up of a Federal Ministry for Environment and Reactor Safety. Finland postponed new orders for nuclear power plants. In Italy and Switzerland, a new petition for banning nuclear power was initiated. The Italian referendum was largely accepted although the impacts of this referendum are still unclear; the Swiss referendum to ban nuclear power there was defeated (WEC, 1989).

It needs to be noted that these political actions did not change the basic nuclear policies in most countries. Those countries already determined to phase out nuclear energy or not to use nuclear energy at all confirmed their decision, while countries with an ongoing nuclear program continued to support nuclear energy, but slowed down expansion of the program and initiated thorough reviews of the existing safety concepts (Flavin, 1987). Greece decided not to pursue further the nuclear option as a result of Chernobyl.

The confusion caused by the lack of intervention levels and inconsistent use of existing standards in the aftermath of Chernobyl led to increased efforts of most European countries to define and promulgate secondary intervention levels on a national and international scale. In late June 1986, the European Community adopted new common standards for cesium, a similar agreement could not be reached for iodine; France and the United Kingdom opted for a more lenient level than West Germany, The Netherlands, Italy, and other members of the EC(Hohenemser \& Renn, 1988).

In addition to specifying intervention levels, which may not be exceeded but may be set lower than prescribed (ALARA), the German parliament passed a new act on the precautionary protection of the population against radiation exposure in December 1986 (Gesetz, 1986). The major goal of the new act is to ensure that a comprehensive monitoring system is in effect for the whole country and that measurement and intervention levels are unified throughout the eleven German states. Since the ALARA principle has also been confirmed as the basic response philosophy in section 1 of the new act, each state has the flexibility to go beyond federal standards. The collection and interpretation of data are clearly the responsibility of federal agencies, but the selection of actions is still state responsibility unless federally determined dose limits are exceeded (SSK, 1987).

\section{Public attitudes after Chernobyl}

Opinion polls to investigate the public attitude towards nuclear energy were conducted in almost every country after the accident (Newsweek, 1986; Wall Street Journal, 1986; Flavin, 1987; Allensbach, 1987; Suhonen \& Virtanen, 1987; Midden \& Verplanken, 
1990). Not surprisingly, support for nuclear power declined in most countries and in spite of some recent recovery has not reached the level of approval of the preChernobyl period. Opposition to nuclear power immediately after the accident peaked in Finland, Yugoslavia, and Greece (over 30\%); considerable increases (over 20\%) were observed in Austria, West Germany, and Italy; moderate changes took place in the United Kingdom, France, The Netherlands, Sweden, and Spain $(12-18 \%)$.

Different survey results suggest that public response was aggravated by poor risk communication (Otway et al., 1987). Frequently, citizens were convinced that the government was withholding information and did not tell the truth $(63 \%$ of the French population, for example). In Germany, well-educated citizens complained that the government did not give enough and adequate information, while less educated citizens felt overwhelmed by the flood of information and opted for more consistent and understandable messages (Peters et al., 1987; Peters, Albrecht, Hennen \& Stegelmann, 1990).

In the U.S.A. which was scarcely affected by the fallout, public opposition to nuclear power gained another $5 \%$ to reach a peak of $49 \%$, the highest percentage ever reported. After the accident at TMI, public support was higher than in the aftermath of Chernobyl (Newsweek, 1986). An even more dramatic change was that the opposition to a nuclear plant in the respondent's neighborhood increased from $45 \%$ in 1976 to $60 \%$ in 1979 and $70 \%$ in May 1986. Recent polls confirm, however, that the level of opposition has almost fallen back to the pre-Chernobyl level (WEC, 1989).

Observers of East-European countries detected a growing opposition to nuclear power in Poland, Hungary, and specifically CSSR (Nucleonic Week, 1986, 1987). Data are only available for Yugoslavia. Three months after the accident the number of opponents towards nuclear energy increased from 40 to $74 \%$. One year after the accident the number of opponents $(64 \%)$ is still $24 \%$ higher than before the accident.

After the initial shock, many supporters of nuclear power who had expressed negative attitudes in the immediate aftermath of Chernobyl changed their opinion again during the months following the accident and regained their initial positive attitude. Figure 1 shows the increase of opposition measured two to three months after the accident, and at least one year after the accident. A considerable decline in public opposition has occurred in each country where data were available. The new numbers are almost proportional to the distribution of opponents observed directly after the accident. Greece and Yugoslavia are still leading the list of countries with the most dramatic changes in attitude; Germany and Italy are in the middle positions, and in France and the United Kingdom, the changes were the least enduring.

The situation is even more complex in the two Scandinavian countries of Sweden and Finland. Two-thirds of the Finnish population who rejected nuclear power as a means of energy production in the aftermath of Chernobyl, changed their opinion within a year and became undecided or even supportive of nuclear power. A monthly poll taken in Finland reveals that the peak of the opposition was reached in summer and early fall 1986, but that opposition declined rapidly in winter 1986/1987 (Suhonen \& Virtanen, 1987). In Sweden, the extended discussion on contaminated game and moose meat triggered a new wave of antinuclear opinion more than 14 months after the accident (WEC, 1989).

In spite of the recovery of public support in most countries, all available data clearly demonstrate that the initial distribution of positions towards nuclear energy has not 


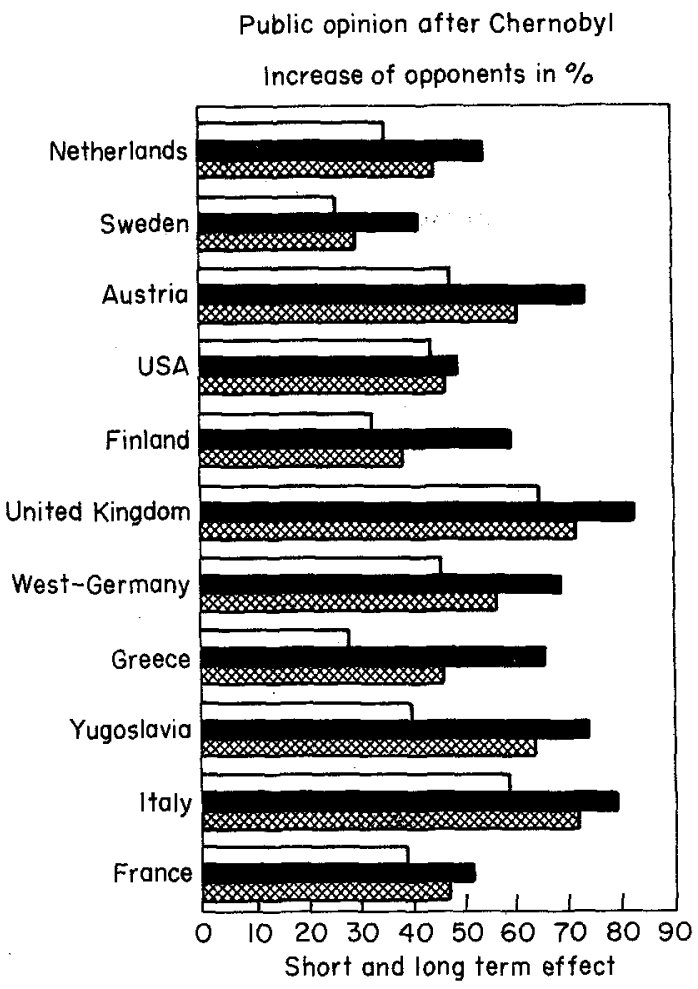

FIGURE 1. The changes of public opinion before, directly after, and one year after the Chernobyl accident in selected countries. $=1987 ; \mathbf{\square}=$ after; $\square=$ before. $^{*}$

* Sources: Flavin 1987; Allensbach 1987; Roser 1988; Suhonen \& Virtanen 1987; Otway et al., 1987.

been reached in any country. One year after the accident it is not clear whether nuclear attitudes will remain negative, or may change again-possibly in both directions.

\section{Explanations for attitude changes}

To gain a better understanding of long-term changes in public attitudes, it is interesting to compare the responses after Chernobyl with those after TMI. The accident at TMI proved to have only a limited effect on public opinion in those countries that were not directly affected by the consequences of the accident and which had a low percentage of undecided positions or 'don't know' responses prior to the accident (Renn, 1984). While US public attitudes after TMI became more critical and remained that way thereafter, Germany, France, Great Britain, and most Scandinavian countries experienced only a short period of increased opposition. Within a year, public confidence in nuclear energy reached pre-TMI levels or was actually even higher. In contrast the population of countries such as Spain and Italy which had a high number of 'don't knows' and uncommitted opinions at that time, became more skeptical about nuclear power and consolidated this skeptical orientation over the following years.

A theoretical explanation for this behavior may be found in the 'inoculation effect' of attitude formation and commitment (McGuire, 1985; Renn, 1984). This effect makes individuals with a positive attitude feel amost immunized against negative incidents, while an uncommitted person may use the incident as an incentive to take a side in the 
debate. The metaphor of inoculation refers to the preparedness of the immunity system to cope with a class of bacteria or virus. Similarly, the mental system tries to avoid the exposure or the storage of information that would induce painful changes of previous attitudes (Cotton, 1985; Frey, 1986). Selective exposure and downplaying of counterevidence are two mechanisms of avoiding cognitive dissonance (Festinger, 1957).

Proponents of nuclear energy who have been inoculated with information about minor incidences in nuclear facilities, react first with the shock response of withdrawing their support, but consolidate their original attitude after a while. This is particularly true for these persons for whom nuclear energy has been a peripheral subject, i.e. a subject or issue that evokes low personal involvement and relevance. As shown, attitudes about peripheral issues tend to be based on heuristic processing and simplified reasoning (Chaiken, 1980; Petty \& Cacioppo, 1986). Arguments and content related reasoning, however, are less prevalent for peripheral issues. If a 'psychologically undeniable' accident occurs, arguments to cope with this event are missing under this route of attitude formation. Instead cues, such as opinions of reference groups, trust in institutions, the alleged viewpoints of the majority, become important orientations in attitude formation and change. These cues are usually negative immediately after the accident, hence the impossibility to find reassurance of existing (positive) attitudes. Over time, professional groups and interest groups provide new positive cues so that the initial shock can be overcome. Such a recovery to the original position requires, however, the existence of counter-evidence, based on reassuring cues, such as a perceived positive opinion of the majority or of highly esteemed reference groups, assurance that the incident was not as severe as originally anticipated, and messages from highly trusted sources that similar events would not reoccur or could not happen in one's native country.

People that regard nuclear energy as a central issue have usually collected enough arguments and are able to cope with large accidents as long as these accidents are not proving the inaccuracy of the previously held beliefs. Transitional cues, such as the immediate response of politicians or interest groups, have less impact on their attitude. But if salient beliefs are at stake, for example, about the nature of nuclear safety, changes of attitudes may occur and are probably stable unless new information becomes available that reassures the initial beliefs. Due to the inoculation effect and previous commitments to a pro-nuclear attitude, such changes are less likely to happen and may extend over a longer period of time. Attitudes may slowly erode over time if salient beliefs are consistently challenged.

The data collected for West-Europe and Yugoslavia allow a quasi-empirical test of the concept of inoculation. If this effect had dominated the response pattern after Chernobyl, the increase in opposition should be a function of two factors: the degree to which people perceive the incidence as counterproving salient beliefs (overcoming the inoculation effect), and the quantity of indifferent and 'don't know' responses towards the issue in question (absence of inoculation effect). Since we lack data measuring the perception of sufficient evidence to change salient beliefs, we hypothesized that such evidence would be proportional to the real danger posed by the incident. The more people are forced to face a health threat of an object associated with favorable attitudes, the more likely it is that salient beliefs would be affected. Therefore, increase in opposition should be proportional to the radiological doses experienced in each country and also be correlated with the number of indifferent positions before the accident. 
The correlation between whole body doses and the increases of public opposition is indeed substantial. The correlation is $0.82(p<0.01)$; the rank order coefficient is 0.79 $(p<0.01)$. The increase of opponents towards nuclear energy is therefore directly proportional to the released body doses. Furthermore, the correlation between the number of indifferent positions before and the number of opponents after the Chernobyl accident is also fairly high. The coefficient $R$ is $0.42(p<0.20)$; the rank order coefficient is $0.54(p<0 \cdot 10)$. The lower correlation coefficients are basically due to the lack of variation in the independent variable and the small sample size; in most WestEuropean countries, less than $5 \%$ had indifferent of 'don't know' positions towards nuclear energy before the Chernobyl accident.

Furthermore, inoculation theory would predict an almost complete recovery of public opinion in countries with strong prior commitments to a specific attitude and weak stimuli to change salient beliefs. Likewise we expect hardly any recovery in countries with a low degree of attitudinal commitment, and the presence of strong stimuli to change salient beliefs. Again we correlated the recovery effect, measured in terms of percent opponents one year after the accident, with the dose received after Chernobyl. The correlation coefficient is almost identical with the one using the number of opponents immediately after the accident. The correlation is $0.79(p<0.01)$ and 0.78 for the rank order correlation. A similar result was obtained for the number of indifferent positions (Spearman $=-0.52$ ).

What long-term effects can we then expect from the Chernobyl accident taking into account the implications of the 'inoculation' concept? The studies undertaken so far about the effects of the Chernobyl accident imply the following pattern: those countries less affected by the fallout and with highly structured attitudes prior to the accident, such as France, the United Kingdom and Spain, exhibited less public concern from the beginning, and within one year public support towards nuclear energy almost reached pre-Chernobyl levels.

West Germany, The Netherlands, Austria, Switzerland, Sweden and Italy were more affected by the fallout, but had highly structured attitudes prior to the Chernobyl accident. Therefore, the initial responses in those countries were much more dramatic than in France, for example, but a significant recovery of pro-nuclear attitudes occurred within the first year after the accident. Finland is probably the best example for the inoculation effect where the initial shock resulted in more than $30 \%$ additional opponents from which two-thirds revised their opinion again during the following year (Suhonen \& Virtanen, 1987). With continuing negative cues, however, persons with a peripheral interest in nuclear power are more inclined to form more negative beliefs about nuclear power and to change their overall attitude.

Another interesting case is Greece. This country, although less affected, had a strong proportion of uncommitted or undecided positions in the nuclear debate. As a result, public opinion changed dramatically and the recovery was only marginal compared with Finland (Otway et al., 1987).

If this pattern prevails, it suggests that revealed attitude changes will only last in those countries which either experienced impacts of the accident and/or had a strong proportion of uncommitted positions prior to the accident. This would mean that public attitudes in the United Kingdom, France, Spain, Ireland, and the U.S.A. will not be strongly affected by the Chernobyl accident in the long run. The attitude changes in Central and Northern European countries may further recover, but will not reach the pre-Chenobyl level (similar to the TMI experiences in the U.S.A.). The opposition to 
nuclear power will, therefore, gain influence in these countries, but may not be able to form a majority. The most dramatic changes are to be expected in countries in which both conditions were met, in particular Poland, Hungary, the CSSR, and Yugoslavia. Except for Yugoslavia, survey data are not available to test this claim.

\section{Protective actions by individuals}

Given all the confusion about protective actions and the changes in public opinion, it is not surprising that many people overreacted and others did not even follow the simplest recommendations. Otway et al. (1987) report the following spontaneous reactions that often led to a higher risk to the individual than the one to be avoided:

- a sudden increase in the number of abortions (reported in Austria and Italy);

- panic buying of tinned, frozen, and other long-life foods, reported in most countries, but reaching near-riot proportions in Greece;

- buying of radiation measuring equipment for personal use (reported in West Germany and Great Britain);

- intake of potassium iodide (sometimes in large overdoses), reported in Poland, West Germany, and Denmark; and

- an increase in suicides partly attributed to inability to cope with the threat, partly attributed to the financial ruin of small firms (reported in Italy and Greece).

German newspapers reported other types of responses, such as removal of topsoil in private gardens, staying indoors for almost two weeks, and burning of clothes worn while there was fallout. Although such overreactions received quite a strong press coverage, they were not at all typical of the majority of the population. As Peters et al. have shown in their study (1990) most respondents in a West Germany survey did not engage in any protective action. In their study, $55 \%$ of the respondents declared that they had not changed their diet after Chernobyl.

A minority of the population, in general better educated and more aware of environmental problems than the average citizen, was extremely worried by the fallout from Chernobyl and responded with corresponding protective actions highly publicized in the media. This minority perceived nuclear energy as a central issue and was convinced that major actions were necessary to cope with the risk. The majority reacted with much more apathy and did not perceive an immediate need for selfprotection. The anger and frustration resulting from confusion and uncertainty about the adequacy of personal reactions were partly channelled towards the object that appeared to have caused all the upset. That is why attitudes towards nuclear power were much more affected by the accident than was personal behavior.

\section{Trust in emergency institutions and information}

Another possible factor that may explain the low compliance rate with official recommendations is the loss of trust and belief in government institutions. For West Germany and the United States, survey results have yielded a clear correlation between attitudes towards nuclear power and confidence in public institutions (Renn, 1984). The study by Peters et al. revealed again an astonishing result for West Germany. In spite of the confusion and contradictions created by the official emergency managers, around $60 \%$ of all respondents indicated that they found the federal government and 
other official institutions, such as the nuclear research centers, totally, or at least partially, trustworthy.

This result may be typical only for Germany since public opinion polls in Italy and France reported $70 \%$ or more of respondents feeling distrust towards and lack of confidence in the government (Otway et al., 1987). Trust in government was not high in these two countries before Chernobyl, and their rather restrictive handling of information may have aggravated this feeling. Although survey data are not yet available, the impressions gained in Sweden and The Netherlands support the notion that there was sufficient confidence in the emergency handling institutions.

The German data suggest that most people had equal confidence in pronuclear and antinuclear institutions (Peters et al., 1987). The (pronuclear) government and the nuclear research centers were trusted to nearly the same degree as their direct adversaries, the (antinuclear) citizens' initiatives and the ecological research institutes. Furthermore, those who trust the pronuclear information sources, do not necessarily mistrust the antinuclear sources.

A large percentage of the population appears to believe that the often contradictory elements of information given by both camps contain a certain amount of truth, and that both sides do not lie deliberately but focus on those aspects that support their general viewpoint. Clearly, confidence in two antagonistic camps add to the confusion experienced in the aftermath of Chernobyl, and caused frustrations from listening to seemingly contradictory sets of recommendations from respected institutions.

The politicalization of the emergency response arena not only added to the confusion of the public, but destroyed the potential role of scientific institutions as arbiters in the conflict between the major interest groups. Scientific institutions proved unable to provide unbiased evidence for orientation and suggestions for effective hazard management. It is doubtful, however, whether the politicization of scientific institutions can ever be reversed.

\section{The role of the media}

The media played a major role in amplifying the dissent among science institutions and in taking part in speculation about potential health effects. The coverage of overreaction and the emphasis on inconsistencies between official recommendations were additional causes of public discomfort and skepticism. But all these phenomena were real and not invented by the media. Overlapping responsibilities, contradictive advice, inability to explain the meaning of specific countermeasures, and total chaos in the units and intervention levels characterized the European scene. Media coverage was merely a reflection of what actually happened in most countries.

Content analyses of the media were conducted in many European countries. In Italy articles in print media were the focus of an investigation on information content, information matter, and expressed biases (Belelli, 1988). The results confirm that the press did not dramatize the effects of Chernobyl and did not distort the factual evidence. Although it may be difficult to assess, correctness of information was evaluated by the investigators and the results compared with the pre-Chernobyl situation.

The basic opinion on nuclear energy that each print medium developed prior to the Chernobyl accident were in general not changed after the accident. A little more than half $(50.3 \%)$ of all Italian newspapers were in favor of nuclear energy before Chernobyl. This number dropped to $48 \cdot 7 \%$ after Chernobyl. This may also be seen as 
an indication of the inoculation effect, this time exerting its influence on an institution rather than an individual.

The most frequently reported subject in Italy's print media was not the accident and its causes and consequences, but the reflections on the domestic nuclear program $(25 \%$ of all analysed articles). Similar results were yielded in a German and a Finnish study (Rager, 1987; Joutsenniemi, 1987). The attention of the media shifted from the accident to the potential danger of domestic nuclear reactors. Most articles or TV reports discussed the future of the nuclear industry in each country. The change of media topics ran parallel to the shift of concern in the general public: the public was less worried about the fallout and the demanded changes in diet, but was concerned about the adequacy and political justification of the domestic nuclear program.

In West Germany, the media coverage peaked on the question of the possibility of a slow or fast phase-out of nuclear energy. Again, it should be emphasized that the discussion in the media was predominantly a reflection of the argumentation among social groups and political parties (in West Germany between the Christian Democrats advocating further use of nuclear energy and the Social Democrats advocating a phaseout within ten years). The media did not provoke this discussion or initiate it. In addition, most German media tried to give justice to both sides of the nuclear debate. Proponents of nuclear energy were just as often cited as opponents (Rager, 1987).

With the exception of the two major TV programs (ARD and ZDF), however, which were well-balanced in presenting pronuclear and antinuclear arguments in their coverage of the Chernobyl accident and its domestic consequences, the print media usually took clear position if favor of or against nuclear energy. Most of the print media ranging from the liberal to the left political spectrum adopted an antinuclear viewpoint, whereas the conservative media, such as 'Die Welt' or 'Frankfurter Allgemeine' voiced a positive opinion towards nuclear energy. The media's points of view correspond, therefore, with the political programs of the conservative and progressive parties, although the liberal party had not finally decided on its policy towards nuclear power. The positions in the parties, as well as in the media, were not initiated through Chernobyl but sharpened and reinforced.

The results of the Finnish study point in the same direction. Management problems concerning the domestic program were the major issues in the print media (Joutsenniemi, 1987). Antinuclear positions were reconfirmed and pronounced more vigorously, but also pronuclear media criticized the government for mismanagement of the crisis and the creation of public confusion.

A media analysis for seven different countries based on print media comes to a similar conclusion (Otway et al., 1987): The coverage was in general accurate and reflected the political debate in each country. Furthermore, the authors revealed that there had been reasonably fair coverage of the event considering the time constraints under which journalists usually operate. Another example of the willingness of the press to cooperate with scientists and to serve public interest was reported in southern Germany. A close cooperation between the scientists of the university here and the local newspaper was established in Constanz which led to an exceptionally wellorganized risk communication and management effort (Hohenemser et al., 1986).

The overall impression of a responsible, accurate, and fair coverage of the event by the media revealed by content analysis can be further substantiated by the subjective perception of the press coverage through public opinion. The study of Peters et al. (1987) indicated that $43 \%$ of all respondents felt that the electronic media covered the 
incident and its consequences in a well-balanced and unbiased way; $14 \%$ regarded the coverage as too negative, $12 \%$ as too positive. Those who detected biases in the media were more likely to be extreme proponents or opponents of nuclear energy, who usually reject anything as biased which does not support their point of view. Once again, the high number of 'don't know' responses is interesting, further proof of the uncertainty created by the official risk communicators.

The common prejudice, that the media were responsible for the confusion and the difficulty to convey the true dimension of the health threat, has to be rejected in the light of the evidence presented here. The media may have aggravated the feeling of confusion and frustration by pointing to the weakness of risk management and the overt contradictions in risk communication. But they only amplified what actually happened in the attempt of government officials to master the crisis. The deficiency of management response was, therefore, neither due to biased media coverage nor as analysed earlier to the lack of confidence in management institutions. It was basically a product of the malperformance of the management institutions.

\section{Lessons for risk management and communication}

The bottom line of the risk management and communication efforts in most European countries is that the degree of protective actions were generally proportional to the threat posed by the radioactive fallout, but that inconsistencies in risk management, downplaying and dramatizing by stakeholder groups, insufficient attempts to provide accurate, unbiased, and effective risk information, and helplessness vis-a-vis overreactions and apathy of public groups all led to suboptimal results and an even more dramatic loss of reputation among the public. Confusion and inconsistencies created a climate of insecurity in which over-reactions and apathy developed simultaneously, depending on the saliency of the nuclear threat to the affected person. Many persons reacted with anger and outrage, and channelled their dissatisfaction with the risk management efforts to an increase in opposition towards the domestic nuclear program.

The Chernobyl accident is a perfect case study of the kind of mistakes and problems in nuclear emergency situations that should be avoided in the future. In fact, the lessons drawn from this case can also be applied to other supranational disasters such as chemical spills. By reviewing the first analyses of the communication and management efforts by European governments and comparing these results with some guidelines developed in the context of risk communication, the following possible improvements in future emergency responses are suggested (Renn, 1988):

(1) The unexpected high variation in local exposure to radiation requires monitoring capability on the community or district level. In order to keep costs low, regional universities or schools of higher education should be equipped with measuring devices and exact guidelines on how to use them. If there is a nuclear emergency, the designated teacher or professor, assisted by students, would be expected to measure radiation levels in the local area. Soil, water, rainfall and food should be investigated. All measurements would have to be reported to the appropriate emergency management institution according to a prearranged plan.

(2) Within each country or, even better, within the European Community or other international bodies (perhaps the IAEA), standards for radiation levels that require protective actions should be determined and promulgated. These universal standards 
should serve three functions: to facilitate the responses of regional management institution by providing clear and unequivocal instructions; to ensure that no group of citizens be exposed to greater risk than others (equity concern); and to convey an easily understandable and comprehensible safety and protection rationale to affected citizens. The threshold for initiating actions should be low enough to convince the public that a sufficient degree of protection can indeed be achieved. Although the ALARA principle would allow different standards for different situations, I believe that consistency and clarity are superior goals to hazard management than costeffective risk minimization.

(3) The type of protective action should correspond to the activity level specified for intervention and tailored to the nature of the local environment. Although a single set of protective actions for each intervention point would be most desirable from the point of view of risk communication, local circumstances and the specific characteristics of the affected region are likely to require differentiated sets of protective actions based, however, on identical standards to avoid confusion. Furthermore, the costs of protective actions may vary from one region to another so that a universal response set would lead to suboptimal solutions. Therefore, responses have to be more flexible, but should be predetermined for each local area. The objective of the flexible response strategy is to accomplish an identical level of public protection using different means.

(4) In addition to public actions based on collective decision making, all citizens should be given the opportunity to increase voluntarily their desired level of safety. This requirement implies, first, that all measures are publicized in the local media and, second, that recommendations about additional means of self-protection are communicated and explained. Leaving actions entirely to individuals would probably lead to an unacceptable violation of equity, because less educated persons find it difficult to make voluntary adjustments and would, therefore, face a much higher risk. Combining an adequate collective safety standard with the opportunity to further reduce risk at an individual level appears to represent the best trade-off between equity and freedom of protective action.

(5) Confidence in the above measures depends on the capability of the emergency manager to put the risk and the effectiveness of countermeasures in perspective, i.e. in relation to other risk situations. Risk comparisons are not well received by most members of the public, because they have been extensively used to justify nuclear power or other low probability/high-consequence risks. Abstract risk figures, however, have hardly any meaning for most of the public. Furthermore, the way in which risk figures are presented (for example, in percentages of additional cancers or in absolute numbers of additional cancers) makes a strong difference to their public perception. Hence, it seems advisable to use the abstract figures in combination with one or two other related risks. The most acceptable approach is to use a reference risk that is also technological in nature and involuntary, such as the risk from food additives or air pollutants. Publishing those risk figures prior to any emergency would be helpful in preparing the public to deal with probabilities and in soliciting responses by interest groups.

(6) For the purpose of gaining public confidence, an institutional separation of emergency response activities and nuclear energy licensing or even promotion is essential. Public concern in Italy peaked when it became known that ENEA (Ente Nationale Energie Nucleare e Alternative) was responsible for both the licensing of 
nuclear power plants and the control of public safety (Otway et al., 1987). Public recommendations were followed more often in those countries where the government was not perceived as an involved party in the nuclear debate.

(7) Apart from any nuclear emergency, the handling of modern technological hazards requires a better understanding of the meaning of probabilities and the risk management process. In the long run, educational programs for schools and professional training should be introduced so that probabilistic thinking is slowly incorporated into the generally accepted notion of common sense. Deterministic heuristics, which still predominate common sense reasoning, prevent many people from evaluating risks consistently and responding to emergencies in a rational manner.

Even if all these suggestions were implemented, over-reaction on the one hand and apathy on the other will still be likely responses to nuclear crises. But a more consistent approach to risk communication and a better preparation for nuclear emergencies could certainly increase the proportion of adequate responses and enhance public protection. Some countries, such as West Germany, have already started to reform their emergency response system. Although the intended unification of intervention thresholds is going in the right direction, the drive to centralize the response system may result in inflexibility and inability to cope with high local variations in exposure. A viable compromise between centralized guidelines and flexible reactions based on local conditions is probably the best solution.

\section{Conclusions}

The accident of Chernobyl did not only leave its mark in the form of radioactive fallout in most European countries, but also had a lasting impact on public opinion and personal attitudes. Attitude theory suggests that in countries with less visible impacts and low percentages of uncommitted or 'don't know' responses, attitude changes will be merely temporary. In most countries affected by the fallout, citizens responded with a more negative attitude toward nuclear power in general, but had difficulties in finding appropriate protective action. A small, but verbal minority took major protective actions which most experts estimated as 'overdone', while the majority did not even comply with rather simple government recommendations.

Antinuclear sentiments among the public peaked in the immediate aftermath of the accident and shifted from the perceived threat of the fallout to the evaluation of the domestic nuclear program. During the first year after the accident, however, most former adherents of nuclear energy were again supporting the use of nuclear power and opted for a moderate share of nuclear energy in their native countries. This is particularly true for countries with a strong nuclear program. People there find enough positive cues and feel comforted by the perception of a majority in favor of using nuclear power. It is known that the perception of 'swimming along with the majority' has a strong impact on attitude recovery and attitude persistence (Chaiken \& Stangor, 1987). However, even those in favor of the domestic use of nuclear power expect changes in domestic policies, in particular in redesigning emergency response systems. Although governmental management institutions were still respected and perceived as at least partially credible, competing information from antinuclear groups were equally well-perceived and trusted.

In many instances, Chernobyl forced governments to respond immediately to public pressure and to reconsider or alter their existing nuclear policies. The most striking 
political reaction in most countries was not to abolish nuclear power, but to reconsider and possibly delay the further construction of nuclear facilities. Countries with commitments to phase out or abolish nuclear energy, such as Austria, Denmark, Ireland, and Sweden, reconfirmed their nation's decision, whilst most countries with ongoing nuclear programs continued to support the further use of nuclear energy but at a lower growth rate or with a longer implementation time. However, many opposition parties in countries with ongoing nuclear programs changed their nuclear policy and pursued their antinuclear position more radically.

The overall analysis reveals that the primary incentive for European governments in responding to the crisis was to initiate dose reduction measures in accordance with the amount of radionuclides dispersed in each country. In addition, the more outraged the public reacted to the accident, the more public officials felt obliged to increase or intensify the measures for dose reductions. Both public outrage and dose savings were less severe in countries with a high share of nuclear power, thus suggesting that public pressure was the primary factor for the release of dose reduction measures, while the share of nuclear energy was only indirectly related to dose savings.

The official stance on nuclear energy has been and continues to be defensive and under severe scrutiny, but the case is certainly not lost for those governments in favor of nuclear energy. In Europe as well as in the United States, Chernobyl triggered the attention of risk manager and the public alike to the question of post-accidental exposure and its management. The growing interest in the ability of official risk managers to plan and implement adequate protective actions has already influenced the licensing procedure for Seabrook (New Hampshire, U.S.A.) and was one of the reasons for abandoning the plan to build a reprocessing plant in Wackersdorf(Bavaria, West Germany). Many public groups demand that risk management should be better prepared to handle emergency situations and that existing plans for evacuation or food monitoring should be re-examined and tested.

After Chernobyl, it has also become more difficult to confine emergency planning to design-based accidents. New nuclear facilities will probably not be licensed unless enough evidence is provided to show that protective actions are sufficient and management provisions adequate to ensure public protection even for a severe accident beyond the design criteria. If the nuclear community is flexible enough to meet this challenge and to introduce new convincing concepts of providing emergency responses for Chernobyl-type accidents including changes in reactor design which physically exclude the possibility of large accidents, the initial shock of Chernobyl and its reflections on public attitude may be overcome and a new era of nuclear power may arise. Otherwise, the fate of nuclear power will be doubtful; the inoculation effect of attitude persistence will probably be insufficient to immunize people from a second Chernobyl should it ever occur.

\section{References}

Allensbach, Institut für Demoskopie. (1987). Public Opinion Poll on Nuclear Energy After Chernobyl. Report for the Atomic Industrial Forum. FRG: Allensbach.

Belelli, U. (1988). Public and media attitudes to nuclear power in Italy. In Uranium Institut. Ed., Uranium and Nuclear Energy: 1987. Proceedings of the Twelfth International Symposium, London, September 204. London: Butterworth.

Chaiken, S. (1980). Heuristic versus systematic information processing and the use of source versus message cues in persuasion. Pers. Social Psychology 39, 752-766. 
Chaiken, S. \& Stangor, C. (1987). Attitudes and attitude change. Annual Review of Psychology 38, $575-630$.

Cotton, J. L. (1985). Cognitive dissonance in selective exposure. In D. Zillman \& J. Bryant, Eds., Selective Exposure to Communication (pp. 11-33). Hillsdale, NJ: Erlbaum.

Covello, V. T., Von Winterfeldt, D. \& Slovic, P. (1986). Risk communication: A review of the literature. Risk Abstracts 3, 171-182.

Department of Energy. (1987). Health and Environmental Consequences of the Chernobyl Nuclear Power Accident. DOE/ER-0332. Springfield, VA: National Technical Information Service.

European Community (1984). Change of directives to assure the protection of the population and therefore against the dangers of ionizing radiation. Bulletin of the Europeam Community 265(27) (October 5). 84/467/EURATOM.

Festinger, L. (1957). A Theory of Cognitive Dissonance. Stanford, CA: Stanford University Press.

Flavin, C. (1987). Chernobyl: The political fallout in western Europe. Forum for Applied Research and Public Policy (Summer): 16-28.

Frey, D. (1986). Recent research on selective exposure to information. Advances in Experimental Social Psychology, 19, 41-80.

Gesetz zum vorsorgenden Schutz der Bevölkerung gegen Strahlenbelastung. 1986. (Strahlenschutzvorsorgegesetz-StrVG) Bundesgesetzblatt, 1, 2610-2614.

Hohenemser, C., Deicher, M., Ernst, A., Hofsass, H., Lindner, G. \& Rechnagel, E. (1986). Chernobyl: an early report. Environment 28, 6-13; 30-43.

Hohenemser, C. \& Renn, O. (1988). Shifting public perceptions of nuclear risk: Chernobyl's other legacy. Environment, 30, 4-11; 40-45.

Joutsenniemi, A. (1987). Chernobyl: Information and media coverage in Finland. Department of Communication at the University of Helsinki and the Research Institute for Social Sciences at the University of Tampere. Helsinki (Tampere, Finland) August 25, 1987.

McGuire, W. J. (1985). Attitude and attitude change. In G. Lindzey \& E. Aronson, Eds., Handbook of Social Psychology, 3, 223-346. New York, NY: Random House.

Midden, C. J. H. \& Verplanken, B. (1990). The stability of nuclear attitudes after Chernobyl. Journal of Environmental Psychology, 10, 111-119.

Newsweek (1986). U.S. fears and doubts: A Newsweek Poll. 30, Nucleonic Week (1986). Antinuclear fallout from Chernobyl continues to wash over Europe. May, 11-13.

Nuclear Energy Agency (NEA). (1988). The Radiological Impact of the Chernobyl Accident in OECD Countries. Paris: OECD-NEA.

Otway, H., Haastrup, P., Cannell, W., Gianitsopoulos, G. \& Paruccini, M. (1987). An Analysis of the Print Media in Europe Following the Chernobyl Accident. Report of the Joint Research Center of the Commission of the European Community. Ispra, Italy: EC.

Peters, H. P., Albrecht, G., Hennen, L. \& Stegelmann, H. U. (1987). Die Reaktionen der Bevölkerung auf die Ereignisse in Tschernobyl. Ergebnisse einer Befragung. Report of the Nuclear Research Center, Jülich, Jül-'Spez-400. Jülich, F.R.G.: KFA.

Peters, H. P., Albrecht, G., Hennen, L. \& Stegelmann, H. U. (1990). 'Chernobyl' and the nuclear power issue in West German public opinion. Journal of Environmental Psychology, 10, 121-134.

Petty, R. E. \& Cacioppo, E. (1986). The elaboration likelihood model of persuasion. Advances in Experimental Social Psychology, 19, 123-205.

Rager, G., Klaus, E. \& Thyen, E. (1987). Der Reaktorunfall in Tschernobyl und seine Folgen in den Medien. Eine inhaltsanalytische Untersuchung. Manuscript, Lecture at the University of Karlsruhe (Karlsruhe, FRG, June 3, 1987).

Reisch, F. (1987). The Chernobyl accident--its impact on Sweden. Nuclear Safety, 28, 29-36.

Renn, O. (1988). Public responses to Chernobyl: Lessons for risk management and communication. In Uraniun Institut Ed., Uraniun and Nuclear Energy: 1987. Proceedings of the Twelfth International Symposium, London, Sept. 2-4, 1987, pp.53-66. London: Butterworth.

Renn, O. (1986). Gedanken und Reflexionen nach dem Unfall von Tschernobyl. Report of the Nuclear Research Center of Jülich. Jülich, FRG: KFA.

Renn, O. (1984). Risikowahrnehmung der Kernenergie. Frankfurt and New York: Campus.

Roser, T. (1988). The social and political impact of Chernobyl in the Federal Republic of Germany. In Uraniun Institut Ed., Uraniun and Nuclear Energy: 1987. Proceedings of the Twelfth International Symposium, London, Sept. 2-4, 1987. London: Butterworth. 
Strahlenschutzkommission. (1987). Scientific Basic Concepts for the Assessment of Derived Levels of Dose and Contamination According to Section 6 of the Precautionary Radiological Protection Act. Strahlenschutzvorsorgegesetz. Bonn, FRG: SSK.

Suhonen, P. \& Virtanen, H. (1987). Public Reaction to the Chernobyl Nuclear Accident. Tampere, Finland: Research Institute for Social Sciences, University of Tampere.

Wall Street Journal. (1986). The NBC news poll on Chernobyl, May 2, 8.

Washington Post. (1986). Reactions to Chernobyl in Europe, May 5, 13.

Wallmann, W. (1987). Chernobyl's impact in West Germany. Forum for Applied Research and Public Policy, Summer, 13-15.

World Energy Conference. (1989). Attitudes toward energy systems. A multinational comparison. In WEC Committee Ed., Energy and the Public. London: WEC. 